\title{
A Damage Mechanics Approach to Life Prediction for a Salt Structure ${ }^{\#}$
}

\author{
K.S. Chan ${ }^{1}$, K.L. DeVries ${ }^{2}$, S.R. Bodner ${ }^{1,3}$, A.F. Fossum ${ }^{2}$, and D.E. Munson ${ }^{4}$ \\ 1 Southwest Research Institute, San Antonio, TX 78238, U.S.A. \\ 2 RE/SPEC Inc., Rapid City, SD 57709, U.S.A. \\ 3 Permanent address: Technion, Dept. of Mech. Eng., Haifa, Israel. \\ 4 Sandia National Laboratories, Albuquerque, NM 87185, U.S.A."*
}

\section{INTRODUCTION}

Excavated rooms in natural bedded salt formations are being considered for use as repositories for nuclear waste. It is presumed that deformation of the rooms by creep will lead to loss of structural integrity and affect room life history and seal efficiency. At projected repository temperatures, two possible fracture mechanisms in salt are creep-induced microcracking in triaxial compression and cleavage in tension. Thus, an accurate prediction of the time of room life and seal degradation requires a reliable description of the creep and damage processes.

While several constitutive models that treat either creep or fracture in salt are available in the literature [1-4], very few models have considered creep and damage in a coupled manner. Previously, Munson and Dawson [1] formulated a set of creep equations for salt based on the consideration of dislocation mechanisms in the creep process. This set of creep equations has been generalized to include continuum, isotropic damage [5] as a fully coupled variable in the response equation [6]. The extended model has been referred to as the Multimechanism Deformation Coupled Fracture (MDCF) model. A set of material constants for the creep and damage terms was deduced based on test data for both clean and argillaceous salt [7-9].

In this paper, the use of the MDCF model for establishing the failure criteria and for analyzing the creep response of a salt structure is demonstrated. The paper is divided into three parts. A summary of the MDCF model is presented first, which is followed by an evaluation of the MDCF model against laboratory data. Finally, finite-element calculations of the creep and damage response of a salt structure are presented and compared against in-situ field measurements.

\section{MULTIMECHANISM DEFORMATION COUPLED FRACTURE (MDCF) MODEL}

The MDCF model extends the Multimechanism Deformation (M-D) model formulated by Munson and Dawson [1] by incorporating creep and damage mechanisms in a coupled manner. The M-D model was formulated from the deformation mechanism map and includes response equations corresponding to three distinct dislocation mechanisms acting in parallel that predominate during creep of salt [10]. In a similar vein, the MDCF model incorporated the damage processes acting in parallel from the fracture mechanism map, which shows the possible fracture mechanisms are creep-induced

\# Work supported by U.S. Department of Energy (DOE), Contract No. DE-AC04-94AL85000. \#\# A U.S. DOE facility. 


\section{DISCLAIMER}

Portions of this document may be illegible in electronic image products. Images are produced from the best available original document. 
microcracking in triaxial compression and cleavage in tension. Because creep damage in salt under triaxial compression is ubiquitous, the continuum damage mechanics approach was adapted in the development of the damage term in the MDCF model.

In the MDCF formulation [6-9], the total strain rate, $\dot{\varepsilon}_{i j}^{t}$, for a solid deformed under isothermal conditions is given as the sum of the elastic strain rate, $\dot{\varepsilon}_{i j}^{e}$, and the inelastic strain rate, $\dot{\varepsilon}_{i j}^{l}$. The inelastic strain rate is described in terms of a generalized kinetic equation that contains creep, damage, and healing terms, as given by [11]

$$
\dot{\varepsilon}_{i j}^{\prime}=\frac{\partial \sigma_{e q}^{c}}{\partial \sigma_{i j}} \dot{\varepsilon}_{e q}^{c}+\frac{\partial \sigma_{e q}^{\omega_{s}}}{\partial \sigma_{i j}} \dot{\varepsilon}_{e q}^{\omega_{s}}+\frac{\partial \sigma_{e q}^{\omega_{t}}}{\partial \sigma_{i j}} \dot{\varepsilon}_{e q}^{\omega_{t}}+\frac{\partial \sigma_{e q}^{h}}{\partial \sigma_{i j}} \dot{\varepsilon}_{e q}^{h}
$$

where $\sigma_{e q}^{c}, \sigma_{e q}^{\omega_{s}}, \sigma_{e q}^{\omega_{s}}, \dot{\varepsilon}_{e q}^{c}, \dot{\varepsilon}_{e q}^{\omega_{s}}$, and $\dot{\varepsilon}_{e q}^{\omega_{t}}$ are power-conjugate equivalent stress measures and equivalent inelastic strain rates for the creep, shear damage, and tensile damage mechanisms, respectively. The parameters represented by $\sigma_{e q}^{h}$ and $\dot{\varepsilon}_{e q}^{h}$ are the conjugate equivalent stress and strain rate measures for damage healing.

In addition to the various equivalent stress measures, kinetic and damage evolution equations were also developed. These equations are not repeated here, but are available in a number of publications. The formulation of the creep term is described in the papers by Munson et al. [1,12], while those for the shear and tensile damage terms are described in the papers by Chan et al. [6-8]. Formulation of the healing term is described in [11]. The effect of clay particles on the creep response of argillaceous salt is treated in [9].

\section{REPRESENTATION OF CREEP FAILURE IN LABOORATORY SPECIMENS}

The material constants in the MDCF model were determined by fitting model calculations to experimental creep curves of rock salt from the Waste Isolation Pilot Plant (WIPP) site. The material constants for WIPP clean and argillaceous salt are presented in [9]. The same sets of material constants have been used for the calculations shown here.

Coupling of creep and damage in the MDCF model allowed calculation of the entire creep curves, including tertiary creep, of WIPP clean and argillaceous salt. Calculated creep curves for WIPP clean salt tested at a stress difference of $25 \mathrm{MPa}$ under a confining pressure of 1 or $15 \mathrm{MPa}$ are compared against the experimental data in Figure 1. The agreement between model calculation and experimental data is considered good because it is within the variability factor of two usually observed in the experimental creep curves.

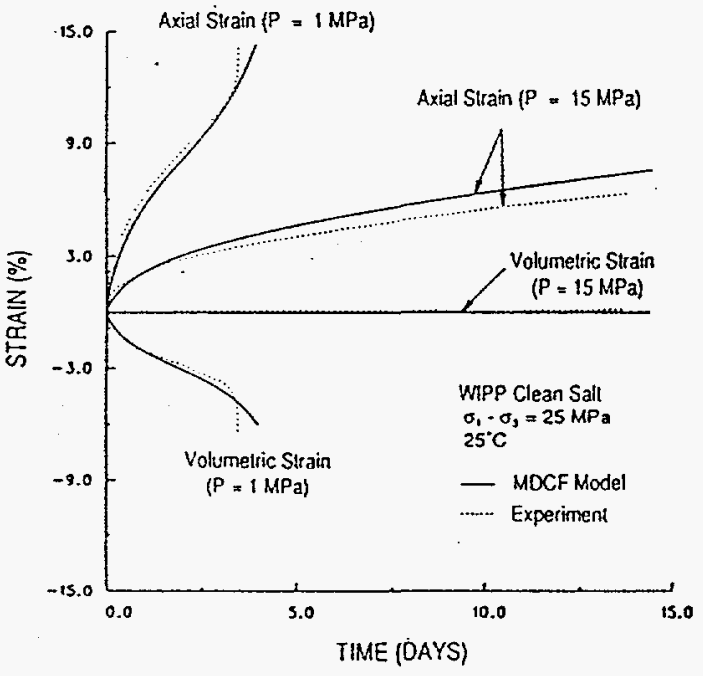

FIGURE 1. Experimental creep data of WIPP salt tested at $\sigma_{1}-\sigma_{3}=25 \mathrm{MPa}$ under a confining pressure, $\mathrm{P}$, of 1 or $15 \mathrm{MPa}$ with comparison to model calculations [8]. 
To elucidate possible failure criteria, a series of creep curves was calculated for clean salt using the MDCF model. For these calculations, the stress difference was $25 \mathrm{MPa}$ and the confining pressure ranged from 0 to $15 \mathrm{MPa}$. The times of creep corresponding to values of the damage variable, $\omega$, of 0.015 and 0.15 were chosen for comparison with the experimental values of the creep rupture time for WIPP clean salt in Figure 2. The result in Figure 2 suggests that a critical value of $\omega=0.15$ may be used as the creep rupture criterion for WIPP salt. Comparison of the calculated and observed minimum creep rates in individual creep curves also revealed that a smaller $\omega$ value of 0.015 may be used as a criterion for representing the onset of tertiary creep.

These $\omega$ values have been used to define an isochronic failure curve or surface for creep rupture. The calculated isochronous curves for a rupture life, $t_{f}$, of infinity is presented in a plot of $\sqrt{J_{2}}$ versus $I_{1}$ in Figure 3 for WIPP clean salt, where $I_{2}$ is the stress deviator and $I_{1}$ is the first invariant of Cauchy stress. At stress states below the calculated curve, damage accumulation, dilatation, and failure by creep rupture are predicted not to occur. The opposite is predicted for stress states above the failure curve. The calculated MDCF isochronic failure curve based on testing creep of clean WIPP salt is also compared with experimental data from a number of salt materials $[13,14]$ in Figure 3, which shows acceptable agreement between model calculation and experimental data. Thus, the conjugated equivalent stress is a good representation of the driving force, and a critical value of $\omega\left(\omega_{\mathrm{f}}=0.15\right)$ is a reasonable measure of the failure condition of creep rupture in WIPP clean salt. Subsequent work indicated the critical $\omega$ criteria are also applicable for predicting the onset of tertiary creep and rupture in WIPP argillaceous salt [9].

\section{LIFE PREDICTION FOR A SALT STRUCTURE}

The WIPP is a research and development facility whose purpose is to demonstrate the safe management, storage, and eventual disposal of nuclear waste. The underground portion of the WIPP facility is approximately 655 meters below the ground surface in massive natural deposits of the Salado Formation in southeastern New Mexico. Pure and argillaceous halite materials are present at the WIPP, together with clay seams, polyhalite beds, and anhydrite beds. 
The SPDV test rooms are a four-room complex that was mined during the early construction phase at the WIPP. The rooms were $3.96 \mathrm{~m}$ in height, $10.06 \mathrm{~m}$ in width, $91.44 \mathrm{~m}$ in length, and were separated by pillars $30.48 \mathrm{~m}$ wide. Each of the rooms was instrumented with several closure stations and extensometers. Only Room 4 was supported, while the other three rooms were intentionally unsupported so that the longterm performance of these unoccupied, barricaded rooms could be studied. Closure of these rooms by creep beyond their intended design life eventually resulted in the loss of structural integrity. Figure 4 illustrates the typical fracture pattern that developed in unsupported experimental rooms at the WIPP for the floor [15] and the roof [16].

The MDCF constitutive model was incorporated into the finite element code SPECTROM-32 [17], which was then utilized to analyze the closure response of the SPDV rooms using material constants for WIPP clean and argillaceous salt. The



FIGURE 4. Composite schematic of observed fracture pattern near unsupported WIPP experimental rooms $[15,16]$.

four-room complex was modeled as a single, one-half room with vertical symmetry planes through the center of the room and the center of the pillar. Figure 5 shows the finite-element mesh used in the plane strain analysis of the SPDV room. A lithostatic initial stress state that varied linearly with depth was assumed and calculated based on the average material density. The calculated initial hydrostatic stress at the repository horizon was $14.8 \mathrm{MPa}$ in compression. To represent the overburden, a $13.57 \mathrm{MPa}$ normal traction boundary was applied to the upper boundary of the structure. Other boundary conditions were (1) zero horizontal displacements on the symmetry plane and on the right boundary, and (2) zero vertical displacements along the bottom boundary. The room was excavated and the reference time set to zero; the closure response of the room was analyzed for 10 years at a constant temperature of $300 \mathrm{~K}$. The initial value of $\omega$ was assumed to be $1 \times 10^{-4}$, while the average clay content for the argillaceous salt was $2.9 \%$. For the calculations presented, only the creep and shear damage terms were operative; the tensile damage and healing terms were not used.

The finite element calculations provided results of the room closure: rates in the vertical and horizontal directions, the distributions of local stresses, volumetric strains, and values of the damage variable, $\omega$. Only results of the damage variable are presented here to illustrate the use of the continuum damage mechanics approach for predicting the failure response and time-to-failure of the SPDV room.

In the formulation, an extremely small initial value of $\omega\left(\omega_{0}\right)$ was assumed as 0.0001 everywhere in the salt structure at time zero. After excavation, damage developed slowly beginning at the comers of the room where stress concentrated. As time elapsed, the damage zone extended outward to form arch-shaped bands that spanned between room corners. The formation and spread of the damage zones with time is illustrated Figure 6 , which shows contours of constant value of the damage variable, $\omega$, for the SPDV room at various times after excavation. Contours of higher $\omega$ values indicate regions with a higher level creep damage. After 0.5 year of creep, arch-shaped damage zones with an $\omega$ value in the range of $0.0001-0.00015$ formed between room corners, as shown in Figure 6 . Additionally, high levels of damage with $\omega$ values of 0.015 and 0.15 developed at the corners of the room. Damage contours of an $\omega$ value greater than 0.015 indicate tertiary creep regions. For $\omega>0.15$, the contours depict ruptured regions, for example, as shown in the floor. With increasing elapsed times, both the tertiary creep zone $(\omega>0.015)$ and the rupture zone $(\omega>0.15)$ expanded outward. After 10 years, an arch-shaped tertiary 
creep zone was fully developed in the roof and pillars and under the floor of the room. Note that the ubiquitous damage model produces a greater spread in the damage zone than observed because localization is not permitted.

A comparison of the results shown in Figures 4 and 6 indicates that the locations of the calculated damage zones and fracture pattern are in excellent agreement with the in-situ field observations. A dish-shaped fracture extended from the floor near the corners of the room through the salt and into the anhydrite below the room. The fracture through the argillaceous halite intersected the floor of the room at approximately the same site where the maximum damage was predicted by the FEM calculations.



FIGURE 5. Structural mesh of the SPDV TRU test panel.

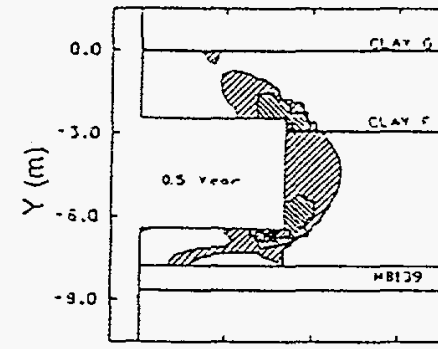

Level of Danage (w)

0.00010



0.00150

0.01500

0.15000

0.30000
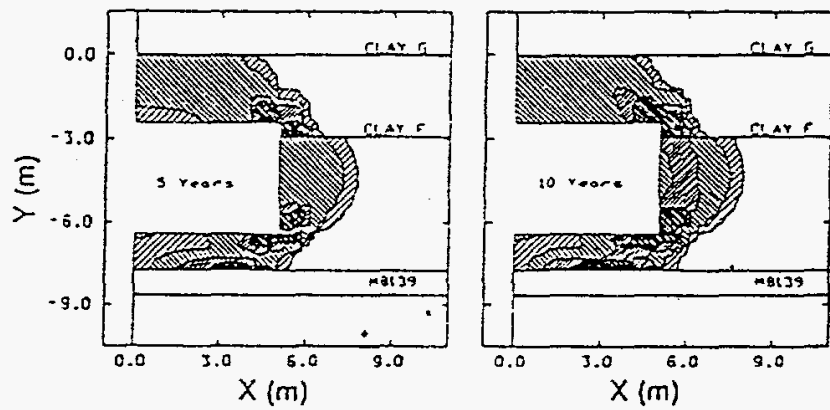

FIGURE 6. Damage level contours near the SPDV test room at $0.5,5$, and 10 years.

- In terms of failure time, the calculated time of fracture formation in the floor was about 10 years after excavation, but was somewhat longer in the roof. In comparison, Room 1 showed signs of instability six years after excavation, and the roof collapsed at approximately eight years after excavation. The rock fall resembled a dish-shaped slab approximately $10 \mathrm{~m}$ wide by $2 \mathrm{~m}$ high and $45 \mathrm{~m}$ in length. The roof of Room 2 fell 11 years after excavating. The roof of the other unsupported room has not failed after 11 years, but its failure may be imminent because of increasing room closure rates. Overall, the calculated failure times for the SPDV rooms are reasonably good estimates, even though a higher accuracy may be required for field applications.

\section{CONCLUSIONS}

Use of the MDCF constitutive model for this first prediction of potential creep failure of an excavated room in a bedded natural salt formation is presented. The critical values of the continuum damage variable at the onset of tertiary creep and at creep rupture have been established based on laboratory data. The constitutive model is utilized in conjunction with a finite-element code to predict damage development in the salt structure. Comparison of finite-element calculations against in-situ field observations indicates that the failure location in the salt structure is accurately predicted. The time-to-failure prediction, while less accurate, is sufficient as a possible indicator of failure. 


\section{REFERENCES}

[1] D. E. Munson and P. R. Dawson, Salt Constitutive Modeling Using Mechanism Maps, Proc. First Intl. Conf. on the Mech. Behavior of Salt, Trans. Tech. Publications, Clausthal, pp. 717-737.

[2] M. Aubertin, D. E. Gill, and B. Ladanyi, A Unified Viscoplastic Model for the Inelastic Flow of Alkali Halides, Mech. Mat., Vol. 11 (1991) pp. 63-82.

[3] M. Aubertin, J. Sgaoula, and D. E. Gill, A Damage Model For Rock Salt: Application to Tertiary Creep, Proc. 7th Symp. on Salt, Elsevier Science Publications, Amsterdam, Vol. 1 (1993) pp. 117-125.

[4] N. Cristescu, A General Constitutive Equation for Transient and Stationary Creep of Rock Salt, Int. J. Rock Mech. Min. Sci. and Geomech. Abstr., vol. 30 (1993) pp. 125-140. [5] L. M. Kachanov, On Creep Rupture Time (in Russian), Izv. Akad. Nauk USSR, Otdgel. Tekh, Nauk., Vol. 8 (1958) pp. 26-31.

[6] K. S. Chan, S. R. Bodner, A. F. Fossum, and D. E. Munson, A Constitutive Model for Inelastic Flow and Damage Evolution in Solids Under Triaxial Compression, Mech. Mat., Vol. 14 (1992) pp. 1-14.

[7] K. S. Chan, N. S. Brodsky, A. F. Fossum, S. R. Bodner, and D. E. Munson, Damage-Induced Nonassociated Inelastic Flow in Rock Salt, Int. J. Plasticity, Vol. 10 (1994) pp. 623-642.

[8] K. S. Chan, S. R. Bodner, A. F. Fossum, and D. E. Munson, Creep Rupture of Rock Salt, submitted for pubiication (1994).

[9] K. S. Chan, D. E. Munson, A. F. Fossum, and S. R. Bodner, Inelastic Flow in Argillaceous Salt, submitted for publication (1995).

[10] D. E. Munson, Preliminary Deformation-Mechanism Map for Salt (with Application to WIPP), SAND79-0076, Sandia National Laboratories, Albuquerque, NM (1979).

[11] K. S. Chan, S. R. Bodner, A. F. Fossum, and D. E. Munson, Constitutive Representation of Damage Healing in WIPP Salt, Proc. 35th U.S. Symp. Rock Mech., Lake Tahoe, CA, June 4-7, 1995, Balkema Pub., Rotterdam (1995), in press.

[12] D. E. Munson, A. F. Fossum, and P. E. Senseny, Advances in Resolution of Discrepancies Between Predicted and Measured In-Situ WIPP Room Closures, SAND88-2948, Sandia National Laboratories, Albuquerque, NM (1989).

[13] L. A. Van Sambeek, A. F. Fossum, G. D. Callahan, and J. Ratigan, Salt Mechanics: Empirical and Theoretical Development, Proc. 7th Symp. on Salt, Elsevier Science Publications, Amsterdam, Vol. 1 (1993) pp. 127-134.

[14] N. S. Brodsky, RE/SPEC, Inc., Rapid City, SD, unpublished research (1994).

[15] D. J. Borns and J. C. Stormont, The Delineation of the Disturbed Rock Zone Surrounding Excavations in Salt, Proc. U.S. Symp. Rock Mech., Balkema, Rotterdam (1989) pp. 353-360.

[16] WIPP Project, The Current Bases for Roof Fall Prediction at WIPP and a Preliminary Prediction for SPDV Room 2, DOE/WIPP, Carlsbad, NM, DOE/WIPP 93-033.

[17] G. D. Callahan, A. F. Fossum, and D. K. Svalstad, Documentation of SPECTROM-32: A Finite Thermômechanical Stress Analysis Program, RE/SPEC Inc., Rapid City, SD, RSI-0269, Vol. 1 and 2 (1990).

\section{DISCLAIMER}

This report was prepared as an account of work sponsored by an agency of the United States Government. Neither the United States Government nor any agency thereof, nor any of their employees, makes any warranty, express or implied, or assumes any legal liability or responsibility for the accuracy, completeness, or usefulness of any information, apparatus, product, or process disclosed, or represents that its use would not infringe privately owned rights. Reference herein to any specific commercial product, process, or service by trade name, trademark, manufacturer, or otherwise does not necessarily constitute or imply its endorsement, recommendation, or favoring by the United States Government or any agency thereof. The views and opinions of authors expressed herein do not necessarily state or reflect those of the United States Government or any agency thereof. 